\title{
Motor skills in extremely low birthweight children at the age of 6 years
}

\author{
N MARLOW, B L ROBERTS, AND R W I COOKE \\ Department of Child Health, Liverpool Maternity Hospital
}

SUMMARY Fifty three children aged 6 years old who had weighed less than $1251 \mathrm{~g}$ at birth without cerebral palsy and receiving mainstream education, were entered into a controlled study of motor skills. The index and control children were matched by age, sex, and school. The index group were considered by their teachers to have similar academic performances to their controls, although two index cases were receiving remedial teaching. On the test of motor impairment extremely low birthweight children had significantly more motor difficulties than controls. In addition, the index group had more minor neurological signs, lower intelligence quotients, and more adverse behavioural traits. The higher motor impairment scores among index children were independent of differences in intelligence quotient between the two groups. There was no association between impairment score and the presence or degree of periventricular haemorrhage or periventricular leucomalacia on neonatal cerebral ultrasound. Children with Apgar scores at five minutes of less than 7 had significantly higher impairment scores compared with those whose scores were 7 or more. Three perinatal factors (Apgar score at five minutes, neonatal septicaemia, and abnormal movements) explained $32 \%$ of the variance in impairment score at the age of 6 years. In children who do not have cerebral palsy perinatal factors may still be important in the development of motor skills. The presence of subtle neuromotor impairments at 6 years of age has implications for schooling that need further evaluation.

During the past decade improved neonatal survival has extended to the smaller low birthweight babies: those weighing less than $1251 \mathrm{~g}$. Despite an appreciable incidence of major neurodevelopment impairments, ${ }^{1}$ most survivors are free of such problems. As yet the long term outcome for the healthy survivors has not been fully evaluated. Although reports of outcome of very low birthweight children born in the $1950 \mathrm{~s}^{2} 3$ and $1960 \mathrm{~s}^{4}$ suggested a high incidence of mental retardation and educational problems, more recent reports suggest that most survivors without major impairment are coping at school. 5

Adverse perinatal events are important in the production of later serious impairments such as cerebral palsy, or deafness, even though in many cases the exact cause remains obscure. Among preterm children the presence of changes on cerebral ultrasound scans has been correlated with later cerebral palsy. ${ }^{6}$ Not all children with abnormal findings, however, go on to develop major impairments. This may be related to the site or extent of the brain injury, or to current methods of assessment.
We became concerned that many of our 3-5 year old survivors seemed rather clumsy on testing, and that this seemed to be independent of their developmental performance, which was normal. Such motor impairment (among children of less than $1001 \mathrm{~g}$ birthweight born between 1960 and 1972) has previously been noted by Nickel $e t$ al, ${ }^{4}$ but in association with poor performance in intelligence tests.

We report a controlled investigation of the neuromotor performance of a cohort of children weighing less than $1251 \mathrm{~g}$ at birth to study the hypotheses that extremely low birthweight children have a disproportionate impairment of motor skills when compared to a matched group of children born at full term and that this impairment is related to adverse perinatal events.

\section{Patients and methods}

Between January 1980 and June 1981, 76 children who weighed less than $1251 \mathrm{~g}$ at birth were discharged from the Mersey Regional Neonatal Inten- 
sive Care Unit at Liverpool Maternity Hospital. At the age of 6 years children were entered into the study if they attended normal school. Four children had died, and 14 with major impairments had been placed in special schools. Of the 58 remaining children, the parents of three declined our offer of assessment. Fifty five children (95\%) were therefore entered into the study.

For each index child a classmate was selected as a control. The head teacher concerned was asked to select from the school register the child of the same sex as the index child who had the nearest birthday. Permission was obtained from the school authorities and the parents of and both index and control children before proceeding.

Each index/control pair was seen at school during the same half day visit, with one exception: one child normally resident abroad was seen at hospital and a control, of similar socioeconomic class, was selected from a local school. Parents were not present during the testing session. The examination comprised: the test of motor impairment, a formal neurological examination, and the Wechsler preschool and primary scales of intelligence (WPPSI). ${ }^{7}$ Subsequently the parents and teachers completed behavioural questionnaires and a full medical and social history was taken. The test of motor impairment (Henderson revision, 1984$)^{8}$ comprises eight items (table 1), which are scored from standards as 0,1 , or 2 . The composite score is termed the impair- ment score, scored from 0 (not impaired) to 16 (severely impaired). The test includes three groups of items: three tests of manual dexterity, two tests of ball skills, and three tests of dynamic balance. It has recently been extensively revised and standardised on large groups of both British and North American children.

In addition to a standard neurological examination, the following minor neurological signs, as described by Touwen, ${ }^{9}$ were sought: dysdiadochokinesia; finger following, circling, opposition, and placing; the finger nose test; dyskinetic movements and, during heel walking, associated hand movements. Mirror movements and associated movements were also recorded according to the method of Fog and Fog. ${ }^{10}$

Behavioural characteristics were evaluated with a 10 item questionnaire. ${ }^{11}$ The parent or teacher was asked to say whether the children were irritable, overactive, difficult to handle, easily frightened, shy, anxious, headstrong, clumsy, fidgety, and how often they had temper tantrums. Answers for each item were graded as the same, more, or less than other children.

Two children were found to have cerebral palsy, both with spastic hemiplegia. One of these had a severe disability, an impairment score of 16 , and serious difficulties in the classroom. The other was only moderately impaired, with an impairment score of 13 , and managing well at school. In view of their

Table 1 Test of motor impairment: combined and individual scores shown as median (interquartile range)

\begin{tabular}{|c|c|c|c|}
\hline & $\begin{array}{l}\text { Extremely low birthweight group } \\
(n=53)\end{array}$ & $\begin{array}{l}\text { Control group } \\
(n=53)\end{array}$ & p Value ${ }^{*}$ \\
\hline \multicolumn{4}{|l|}{ Combined scores: } \\
\hline Manual dexterity & $2.5(1 \cdot 5-3 \cdot 5)$ & $1.5(0 \cdot 5-2 \cdot 5)$ & 0.001 \\
\hline Ball skills & $2 \cdot 0(0-3)$ & $1.0(0-1)$ & 0.008 \\
\hline Dynamic balance & $1.5(0.5-3 \cdot 75)$ & $0 \cdot 0(0-1)$ & $0 \cdot 001$ \\
\hline \multicolumn{4}{|l|}{ Individual tests: } \\
\hline \multicolumn{4}{|l|}{ Posting coins: } \\
\hline With dominant hand (secs) & $21(18 \cdot 5-21 \cdot 5)$ & $19(17 \cdot 5-20 \cdot 5)$ & $0 \cdot 004$ \\
\hline With other hand (secs) & $22(20-24)$ & $21(19-23)$ & $0 \cdot 013$ \\
\hline Thread 12 cubes (secs) & $64(53-81.5)$ & $55(47 \cdot 5-65.5)$ & $0 \cdot 008$ \\
\hline Flower trail (No of errors) & $3(2-5 \cdot 5)$ & $2(0-4 \cdot 5)$ & 0.05 \\
\hline Catches (out of 10) & $8(5-9)$ & $9(8-10)$ & 0.007 \\
\hline Goals (out of 10 ) & $7(5-8)$ & $8(7-10)$ & 0.001 \\
\hline Stand on dominant leg (secs) & $15(8-15)$ & $15(15-15)$ & 0.003 \\
\hline Stand on other leg (secs) & $9(5-15)$ & $15(10-15)$ & 0.003 \\
\hline Toe walking (out of 15) & $12(7 \cdot 5-15)$ & $15(15-15)$ & $<0.001$ \\
\hline \multicolumn{4}{|l|}{ Jump cord: } \\
\hline Pass at knee height & 42 & 49 & \\
\hline Pass at lower height & 6 & 3 & $0 \cdot 1197$ \\
\hline Fail & 5 & 1 & \\
\hline Total score & $6 \cdot 0(4 \cdot 0-8 \cdot 75)$ & $3 \cdot 0(1 \cdot 5-4 \cdot 5)$ & $<0.001$ \\
\hline
\end{tabular}

${ }^{*}$ Mann-Whitney U test. 
overt motor problems they have been excluded, with their controls, from the subsequent analysis.

All children were scanned routinely in the newborn period using an ATL 805A scanner with a $5 \mathrm{MHz}$ probe. Cerebral ultrasound scan findings were reviewed from still photographs without knowledge of findings at the age of 6 years. Perinatal events were abstracted from clinical records. Appropriateness of birth weight for gestational age was assessed by computing a standard deviation score, using the standards of Keen and Pearse. ${ }^{12}$ This was then analysed both as a continuous and dichotomous variable by choosing different cut off points.

The data was coded for computer analysis by the Statistical Package for the Social Sciences (SPSSx) software package. The significance of the various comparisons was tested using non-parametric tests: the Mann-Whitney U test, the Kruskal-Wallis one way analysis of variance, the $\chi^{2}$ test, and Spearman's rank correlation test, as appropriate. Multiple regression was carried out using the SPSSx regression option selecting a ' $F$ ' value for entry of 0.1 and the model selected with the least standard error.

\section{Results}

\section{DEMOGRAPHIC DETAILS}

All control subjects were born at full term and, with one exception, were of appropriate weight for gestational age. No significant neonatal problems were reported by their mothers. Their median birth weight was $3760 \mathrm{~g}$ (range 2350-4760). Of the index group, 21 weighed less than $1000 \mathrm{~g}, 42$ were of less than 30 weeks' gestation, and seven were small for gestational age (less than two standard deviations below the mean). The age distribution of the two samples was well matched. There was no significant difference between the two populations in social groupings and home ownership (table 2). Similar proportions lived with their natural parents, or had single mothers, and the maternal age distribution was similar. Significantly more index children were only children $(p=0.001)$ and they tended to be older members of smaller sibships. The control group, however, had spent an average of three months more in school $(p=0.037)$, although this difference disappeared when the total time spent in full time nursery and school education was considered.

Each class teacher was asked to grade each child's ability into one of three categories. There were no significant differences in the proportions of index or control children who were in above and below average groups, although 15 index children $(28 \%)$, including two in remedial classes, were felt to be below average compared with only eight control subjects $(15 \%)$, and only nine index children were performing in the above average category compared with 16 control subjects.

\section{TEST OF MOTOR IMPAIRMENT}

In contrast to their classroom performance, the extremely low birthweight children were considerably more impaired than their matched controls. The median (range) for the index group was 6.0 $(0 \cdot 0-15 \cdot 5)$ compared with $3 \cdot 0(0 \cdot 0-13 \cdot 0)$ for controls (table 1). On seven of the eight individual items of the test the extremely low birthweight group performed significantly less well than the control subjects (table 1). Despite a large overlap of results only 10 extremely low birthweight children had equal or lower scores than their matched control (figure).

WECHSLER PRESCHOOL AND PRIMARY SCALES The extremely low birthweight children had signifi-

Table 2 Demographic details of index and control groups

\begin{tabular}{|c|c|c|}
\hline & $\begin{array}{l}\text { Extremely low } \\
\text { birthweight group } \\
(n=53)\end{array}$ & $\begin{array}{l}\text { Control } \\
\text { group } \\
(n=53)\end{array}$ \\
\hline \multicolumn{3}{|l|}{ Median (range) birth } \\
\hline $\begin{array}{l}\text { Median (range) gestation } \\
\text { (weeks) }\end{array}$ & $28 \cdot 5(24-35)$ & (e) \\
\hline No of boys & 33 & 33 \\
\hline \multicolumn{3}{|c|}{ Median (interquartile range) } \\
\hline \multicolumn{3}{|l|}{ Socioeconomic class: } \\
\hline I and II & 12 & 13 \\
\hline III & 17 & 23 \\
\hline IV, V or unemployed & 19 & 14 \\
\hline \multirow{2}{*}{\multicolumn{3}{|c|}{ Housing: }} \\
\hline & & \\
\hline Council, rented & 22 & 14 \\
\hline Private, rented & 4 & 7 \\
\hline Private, owned & 27 & 32 \\
\hline \multicolumn{3}{|l|}{ Both natural parents } \\
\hline at home & 38 & 44 \\
\hline \multicolumn{3}{|l|}{ No of siblings: } \\
\hline None & $17^{*}$ & $2^{*}$ \\
\hline 1 & 16 & 29 \\
\hline 2 & 15 & 12 \\
\hline 3 & 4 & 8 \\
\hline 4 & 0 & 0 \\
\hline 5 & 1 & 2 \\
\hline \multicolumn{3}{|l|}{ Rank in sibship: } \\
\hline One & 12 & 18 \\
\hline Two & 14 & 20 \\
\hline Three & 7 & 8 \\
\hline More than three & 3 & 5 \\
\hline \multicolumn{3}{|l|}{$\begin{array}{l}\text { Median (interquartile range) } \\
\text { full time nursery and } \\
\text { school attendance }\end{array}$} \\
\hline
\end{tabular}

${ }^{*} p<0 \cdot 001, d f=5, \chi=^{2}$ test. 

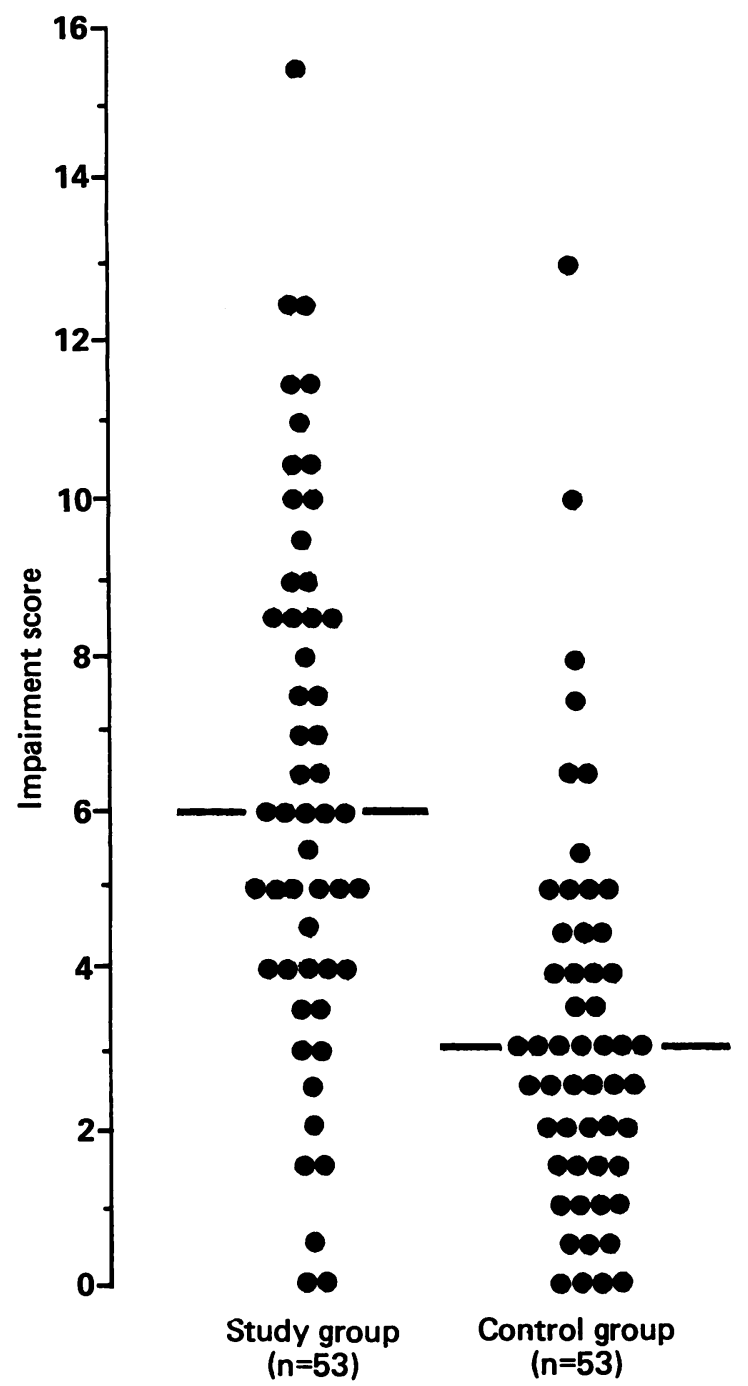

Figure Distribution of impairment scores in study and control groups. The horizontal bar indicates the median.

cantly lower intelligence quotients than control subjects, there being an eight point difference in median scores between index and controls (table 3 ). These differences persisted when both the verbal and performance aspects of the test were considered. The discrepancy between verbal and performance scores, which might be expected to indicate motor impairment, did not vary significantly between groups, indicating that the index group had an overall reduction in scores compared with control subjects.
Table 3 Results of intelligence testing. Values are shown as medians (interquartile ranges)

\begin{tabular}{|c|c|c|c|}
\hline & $\begin{array}{l}\text { Extremely low } \\
\text { birthweight } \\
\text { group } \\
(n=53)\end{array}$ & $\begin{array}{l}\text { Control } \\
\text { group } \\
(n=53)\end{array}$ & $\stackrel{p}{\text { Value }}$ \\
\hline $\begin{array}{l}\text { Intelligence quotient: } \\
\text { Range }\end{array}$ & $\begin{array}{l}109(100-119) \\
82-139\end{array}$ & $\begin{array}{l}117(109-128) \\
84-139\end{array}$ & 0.001 \\
\hline $\begin{array}{l}\text { Verbal quotient: } \\
\text { Information } \\
\text { Vocabulary } \\
\text { Arithmetic } \\
\text { Similarities } \\
\text { Comparisons }\end{array}$ & $\begin{aligned} 112 & (102 \cdot 5-124) \\
15 & (13-17) \\
28 & (24-32 \cdot 5) \\
13 & (12-15) \\
15 & (11-18) \\
21 & (17-24)\end{aligned}$ & $\begin{aligned} 117 & (109 \cdot 5-131) \\
16 & (14-18) \\
31 & (26-34) \\
14 & (13-16) \\
16 & (12 \cdot 5-19) \\
21 & (20-26)\end{aligned}$ & $\begin{array}{l}0 \cdot 05 \\
0 \cdot 04 \\
0 \cdot 11 \\
0 \cdot 005 \\
0 \cdot 07 \\
0 \cdot 15\end{array}$ \\
\hline $\begin{array}{l}\text { Performance quotient: } \\
\text { Animal house } \\
\text { Picture completion } \\
\text { Mazes } \\
\text { Geometric design } \\
\text { Block design }\end{array}$ & $\begin{aligned} 100 & (93-107 \cdot 5) \\
112 & (90 \cdot 5-131) \\
15 & (12-16 \cdot 5) \\
16 & (12-18 \cdot 5) \\
12 & (9-16 \cdot 5) \\
15 & (11-16 \cdot 5)\end{aligned}$ & $\begin{array}{l}111(103 \cdot 5-119) \\
105(74-123) \\
16(13-18) \\
20(16-23) \\
18(15-21) \\
15(14-17)\end{array}$ & $\begin{array}{c}<0.001 \\
0.06 \\
0.005 \\
<0.001 \\
<0.001\end{array}$ \\
\hline $\begin{array}{l}\text { Verbal/performance } \\
\text { discrepancy } \\
\text { Range }\end{array}$ & $\begin{array}{l}+11(4 \cdot 5-23) \\
-30 \text { to }+36\end{array}$ & $\begin{array}{l}+9(-0 \cdot 5 \text { to } 16 \cdot 5) \\
-16 \text { to }+31\end{array}$ & 0.7 \\
\hline
\end{tabular}

${ }^{*}$ Mann-Whitney U test.

The extremely low birthweight children performed significantly less well than controls on five of the 10 subscales of the WPPSI: two verbal subscales (information and arithmetic) and three performance items (picture completion, mazes, and geometric design).

\section{BEHAVIOURAL CHARACTERISTICS}

Of the 10 items considered there was an excess of adverse features among the index group (table 4). There was a strong correlation between the parents' and the teachers' ratings (Spearman's rank correlation: $r=0.292 ; p=0.02$ ), and both sets of observers recorded the index group as being significantly more overactive, easily frightened, and clumsy. In addition the teachers rated the index group as being more fidgety. Both testers (NM and BLR) subjectively agreed that many extremely low birthweight children were inattentive or distractable.

NEUROLOGICAL FINDINGS

Minor neurological signs were more common and more pronounced among the extremely low birthweight group compared with control subjects (table 5). This was especially true for dystonic movements, dysdiadochokinesia, and associated movements, all of which were found significantly more often among the extremely low birthweight children (table 6). The presence of these neurological signs correlated 
with the impairment score (all signs: $r^{2}=0 \cdot 235$, $\mathrm{p}=<0.0001$; pronounced signs: $\mathrm{r}^{2}=0.242$, $\mathrm{p}=<0.0001)$.

Using the two tests described by Fog and Fog ${ }^{10}$ the extremely low birthweight children had more mirror $(p=0.011)$ and associated movements $(\mathrm{p}=0.009)$.

\section{Table 4 Behavioural data}

\begin{tabular}{|c|c|c|c|c|c|c|}
\hline & \multicolumn{2}{|c|}{$\begin{array}{l}\text { Extremely low } \\
\text { birthweight } \\
\text { group }\end{array}$} & \multicolumn{2}{|c|}{$\begin{array}{l}\text { Control } \\
\text { group }\end{array}$} & \multirow[t]{2}{*}{$x^{2}$} & \multirow[t]{2}{*}{$p$ Value } \\
\hline & More & Less & More & Less & & \\
\hline \multicolumn{7}{|l|}{ Parents' judgement: } \\
\hline Irritable & 9 & 5 & 6 & 9 & & \\
\hline Overactive & 25 & 2 & 10 & 4 & $9 \cdot 54$ & 0.009 \\
\hline \multicolumn{7}{|l|}{ Difficult to } \\
\hline handle & 10 & 12 & 8 & 16 & & \\
\hline Easily frightened & 19 & 5 & 8 & 13 & $8 \cdot 18$ & 0.017 \\
\hline Shy & 8 & 20 & 3 & 16 & & \\
\hline Anxious & 16 & 3 & 18 & 1 & & \\
\hline Headstrong & 23 & 3 & 18 & 1 & & \\
\hline Temper tantrums & 4 & 9 & 10 & 10 & & \\
\hline Clumsy & 12 & 5 & 4 & 15 & $9 \cdot 05$ & $0 \cdot 011$ \\
\hline Fidgety & 21 & 6 & 13 & 12 & & \\
\hline \multicolumn{7}{|l|}{ Teachers' judgment: } \\
\hline Irritable & 9 & 14 & 1 & 20 & & \\
\hline Overactive & 13 & 16 & 3 & 8 & $13 \cdot 5$ & 0.001 \\
\hline \multicolumn{7}{|l|}{ Difficult to } \\
\hline handle & 10 & 13 & 3 & 20 & & \\
\hline Easily frightened & 17 & 3 & 4 & 9 & $11 \cdot 68$ & 0.003 \\
\hline Shy & 11 & 16 & 12 & 12 & & \\
\hline Anxious & 24 & 4 & 15 & 6 & & \\
\hline Headstrong & 12 & 11 & 7 & 12 & & \\
\hline Temper tantrums & 5 & 16 & 1 & 20 & & \\
\hline Clumsy & 20 & 4 & 4 & 9 & $22 \cdot 79$ & 0.0001 \\
\hline Fidgety & 20 & 10 & 8 & 15 & $7 \cdot 01$ & 0.03 \\
\hline
\end{tabular}

Because of the correlation between impairment score and both intelligence quotient $(p=0.0001)$ and neurological signs $(\mathrm{p}=<0.0001)$, multiple regression analysis was carried out to explore the association between impairment score and birth weight (coded as a dichotomous variable: $<1251 \mathrm{~g} ;>1251 \mathrm{~g}$ ), including demographic variables in the analysis (as indicated in table 2) and intelligence quotient. Using a forward stepwise technique, birthweight entered the model first $\left(r^{2}: 0 \cdot 21\right)$ and then intelligence quotient. These two variables contributed $25 \%$ of the variance in impairment score $(\mathrm{F}=20.92$, $\mathrm{p}=<0.0001)$. No further demographic variables contributed significantly to the model. Of all outcome variables the total number of minor neurological signs present correlated best with impairment score $\left(r^{2}: 0 \cdot 24\right)$.

Table 5 Minor neurological signs

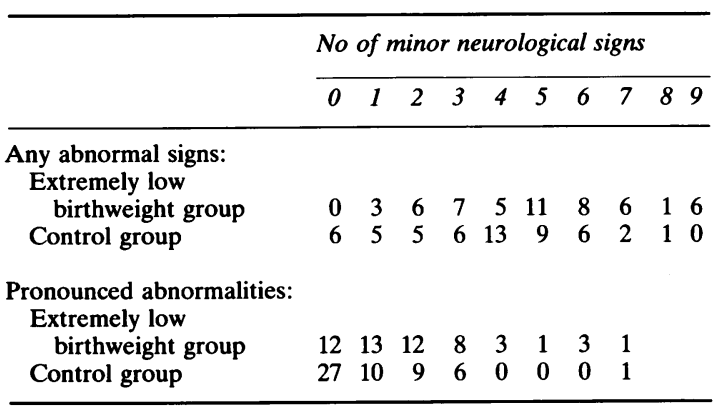

Extremely low birthweight group compared with control group: any sign $p=0.03$, pronounced signs $p=0.002$ (Mann-Whitney $\mathrm{U}$ test).

Table 6 Neurological data

\begin{tabular}{|c|c|c|c|c|c|c|c|c|}
\hline & \multicolumn{3}{|c|}{ Extremely low birthweight group } & \multicolumn{3}{|c|}{ Control group } & \multirow[t]{2}{*}{$\chi^{2}$} & \multirow{2}{*}{$\begin{array}{l}p \\
\text { Value }\end{array}$} \\
\hline & None & Slight & Pronounced & None & Slight & Pronounced & & \\
\hline \multicolumn{9}{|l|}{ Fog test: } \\
\hline Mirror movements & 4 & 35 & 12 & 17 & 27 & 11 & $8 \cdot 98$ & 0.01 \\
\hline Associated movements & 14 & 16 & 21 & 28 & 18 & 9 & $9 \cdot 45$ & 0.009 \\
\hline \multicolumn{9}{|l|}{ Other signs: } \\
\hline Hypotonicity of limbs & 45 & 7 & 1 & 53 & 2 & 0 & & \\
\hline Truncal unsteadiness & 38 & 15 & 0 & 46 & 9 & 0 & & \\
\hline Dystonic movements & 23 & 25 & 5 & 37 & 17 & 1 & $7 \cdot 42$ & 0.02 \\
\hline Dysdiadochokinesis & 5 & 19 & 29 & 14 & 24 & 17 & $7 \cdot 94$ & $0 \cdot 02$ \\
\hline Finger/nose test & 46 & 5 & 2 & 54 & 1 & 0 & & \\
\hline Finger placing & 36 & 16 & 1 & 41 & 10 & 4 & & \\
\hline Finger opposition & 25 & 14 & 14 & 22 & 25 & 8 & & \\
\hline Follow a finger & 25 & 15 & 13 & 35 & 15 & 5 & & \\
\hline Circle-opposites & 42 & 8 & 3 & 49 & 5 & 1 & & \\
\hline Circle-together & 20 & 17 & 16 & 30 & 16 & 9 & & \\
\hline $\begin{array}{l}\text { Heel walking: } \\
\text { associated movements }\end{array}$ & 19 & 15 & 19 & 31 & 18 & 6 & $9 \cdot 88$ & $0 \cdot 007$ \\
\hline
\end{tabular}


PERINATAL CORRELATES

Twenty children (38\%) had neonatal periventricular haemorrhages, 10 subependymal, eight intraventricular, and two parenchymal haemorrhages. Seven children $(13 \%)$ had persistent parenchymal changes. No association between periventricular haemorrhage or parenchymal lesions and impairment score was observed (table 7).

Table 7 Impairment score and neonatal ultrasound findings

\begin{tabular}{lll}
\hline Ultrasound finding & $\begin{array}{l}\text { No of } \\
\text { infants }\end{array}$ & Impairment score \\
\hline No haemorrhage & 33 & $7 \cdot 0(0-12 \cdot 5)$ \\
Subependymal & 10 & $5 \cdot 5(0-15 \cdot 5)$ \\
Intraventricular & 8 & $6 \cdot 0(4-11)$ \\
Parenchymal (unilateral) & 2 & $1 \cdot 5$ and $4 \cdot 5$ \\
Persisting ventricular dilatation & 3 & $4 \cdot 0,10 \cdot 0$, and $10 \cdot 5$ \\
Small cysts (<1 cm): & & \\
$\quad$ Right occipital cysts & 2 & $6 \cdot 5$ and $8 \cdot 5$ \\
$\quad$ Bilateral parietal cysts & 1 & $1 \cdot 5$ \\
Large cysts (>1 cm): & 1 & $4 \cdot 0$ \\
$\quad$ Right occipital cyst & 1 & \\
\hline
\end{tabular}

Table 8 Perinatal clinical factors. Values are shown as median (range) or number with factor, as appropriate

\begin{tabular}{|c|c|}
\hline Birth weight (g) & $1050(630-1250)$ \\
\hline Gestation (weeks) & $28 \cdot 5(24-35)$ \\
\hline $\begin{array}{l}\text { Birth weight/gestational age standard } \\
\text { deviation score }{ }^{*}\end{array}$ & $-0.54(-3.85$ to +2.18$)$ \\
\hline Twin pregnancy & 12 \\
\hline Antenatal problems: & \\
\hline Bleeding $<20$ weeks & 6 \\
\hline $\begin{array}{l}\text { Antepartum haemorrhage as an } \\
\text { indication for delivery }\end{array}$ & 8 \\
\hline $\begin{array}{l}\text { Pre-eclampsia as an indication for } \\
\text { delivery }\end{array}$ & 8 \\
\hline Prolonged membrane rupture & 9 \\
\hline $\begin{array}{l}\text { Mother taking } \beta \text {-agonists antepartum } \\
\text { for longer than } 12 \text { hours }\end{array}$ & 20 \\
\hline $\begin{array}{l}\text { Mother taking steriods antepartum } \\
\text { for longer than } 24 \text { hours }\end{array}$ & 13 \\
\hline $\begin{array}{l}\text { Fetal distress as an indication } \\
\text { for delivery }\end{array}$ & 13 \\
\hline Route of delivery: & \\
\hline Breech & 12 \\
\hline Caesarean section & 20 \\
\hline Apgar score: & \\
\hline At 1 minute & $4(2-7)$ \\
\hline At 5 minute & $9(7-10)$ \\
\hline Intubated at delivery & 30 \\
\hline Ventilated before admission & 24 \\
\hline Bruising noted & 14 \\
\hline Hyaline membrane disease & 37 \\
\hline Septicaemia & 7 \\
\hline Abnormal movements & 4 \\
\hline Fits & 8 \\
\hline Ventilation $(n=40)$ & 3 days $(1-28)$ \\
\hline
\end{tabular}

*Standard deviation score=birth weight-mean birth weight for gestation/standard deviation of birth weight.
Within this very low birthweight group no effect of birthweight, gestational age, or intrauterine growth could be shown. Analysis of single factors (table 8) showed that only an Apgar score at five minutes of less than seven was significantly associated with an impairment score at the age of 6 years (Mann-Whitney U test: $p=0 \cdot 014$ ).

Forward stepwise multiple regression analysis showed that three perinatal variables were associated with impairment score. A decreasing Apgar score at five minutes, proven neonatal septicaemia, and the presence of abnormal movements were associated with higher (worse) scores (r: 0.566). Together these factors explained $32 \%$ of the variance in impairment scores.

\section{Discussion}

Although major motor impairment or cerebral palsy is a common finding among extremely low birthweight infants who survive, few studies have considered the less severe impairments. The present study supports the hypothesis that such children have a range of motor problems from the most severe (those with cerebral palsy who were not included in this study) to less disabling impairments. Most of our study group (all of whom were considered neurologically normal) have obvious motor problems over the whole range of skills tested, including significant differences between index and control children in seven of the eight test items.

Using tests related to the currently used test of motor impairment, three previous studies have reported impaired motor performance in perinatally disadvantaged children born between 1960 and 1972; those weighing under $1000 \mathrm{~g}$ at birth,${ }^{4}$ under $1500 \mathrm{~g},{ }^{13}$ and those born preterm. ${ }^{14}$ Only the latter two studies included controls, and both showed impaired performance among their respective study groups over a wide range of tests encompassing intelligence quotient, perception, and behaviour. Our data confirm that such impairments are still common among children with the lowest birth weights despite improvements in care and survival. The association between intelligence quotient and motor impairment score (although it showed a weak correlation) was not linear, there being a wide scatter of results. The extremely low birthweight group did significantly less well on five of the subscales, two verbal items (information and arithmetic), and three performance items (picture completion, mazes, and geometric design). An association between clumsiness at school entry and later school problems, including poor arithmetic skills, has previously been noted. ${ }^{15}$ Similarly, perceptual problems were reported in earlier studies of low 
birthweight ${ }^{1617}$ and very low birthweight ${ }^{18}$ children, supporting our finding of poor scores on the three performance items. The discrepancy between verbal and performance scores did not vary significantly between our two groups. This is surprising in view of the commonly held belief that such a discrepancy denotes poor motor/perceptual skills. Other studies, however, have also failed to find this measure useful. ${ }^{16} 19$ Language difficulties have been noted among very low birthweight children, ${ }^{20}$ and may also contribute to the reduction in intelligence quotients.

The importance of having a control group must be stressed. In the general population an upward drift in intelligence quotients with time has been observed.21 The scores of the index children observed in this study compare favourably with a notional mean of 100 , but the use of classmate controls who, by their teachers' assessment, are performing at the same level as the study group, shows that this comparison is false. A recent very low birthweight cohort was found to have similar results to those reported here. ${ }^{22}$ In addition, the median motor impairment score for controls (3.0) was higher than standardisation median of just under $1 \cdot 0{ }^{8}$ As with any test, the test of motor impairment may be interpreted in various ways. Although some children had a clear motor disability with high impairment scores, most seemed clinically normal. Controls are also essential for the interpretation of both minor neurological signs, which are subjective observations, and the assessment of behaviour profiles.

The control group were randomly selected by the head teachers, who were asked to select the child with the nearest birthday to the index case. Using such classroom controls a good socioenvironmental match was obtained, although the controls had a slight excess of social class I-III, and home owners. In contrast, the extremely low birthweight group had significantly fewer siblings and were more likely to be only children. These factors would operate in favour of the extremely low birthweight group. ${ }^{23}$ The measures on which this match are assessed are necessarily crude. A recent study reported that most of the variance in outcome at 10 years between low birthweight children $(<2500 \mathrm{~g})$ and well matched controls could be explained in socioenvironmental terms. ${ }^{17}$ In so far as we have been able to control for such factors (table 2) no significant influence has been shown. We believe that the differences in motor impairment score shown here are of such a magnitude that they rule out such a influence. Indeed, despite the anticipated weak correlation between intelligence quotient and motor impairment score, the most important correlate of the six year impairment score was the birthweight group.

The inclusion of a detailed neurological examination shows that minor neurological signs are often found among normal 6 year olds, but are especially common among extremely low birthweight survivors, who had significantly more dyskinesia, dysdiadochokinesia, and dystonia. Low birthweight children with an excess of 'soft' neurological signs have been reported to receive more special education and more psychiatric referrals. ${ }^{16}{ }^{24}$ In addition, although motor difficulties may disappear at a later age, children with 'soft' signs identified at early school age continue to show minor neurological deviancy at $10^{16}$ and 17 years of age,$^{25}$ together with affective and anxiety disorders. These 'soft' signs comprise a mixture of items ranging from minor neurological signs as defined here to items from motor performance tests. All the six year outcome variables described in the present study are statistically related, but using multiple regression analysis the number of minor neurological signs has the strongest correlation with motor impairment score, suggesting an organic basis for the observed motor impairment. Recent studies have reported a high frequency of attention/deficit disorder among low birthweight ${ }^{16}$ and very low birthweight ${ }^{22}$ children. This diagnostic category ${ }^{26}$ comprises several different characteristics, including neuromotor, behavioural, and attentional problems, many of which were present in our children. In this study there was good agreement between both parents and teachers that the index children were more likely to be clumsy, overactive, and more easily frightened. Teachers considered the index children to be more fidgety. During the examination both examiners independently recorded that many of the extremely low birthweight children subjectively had short attention spans and were more distractable. The test of motor impairment comprises short items that are easy to understand and perform. It is unlikely that attentional deficits contributed greatly to the pronounced differences in motor skills that were seen, though clearly they would contribute to school performance.

Previous studies of very low birthweight children have had only limited success in the definition of perinatal antecedents of major disabilities. Individual studies have identified comparatively few clinical associations, such as low Apgar scores, ${ }^{27}$ mechanical ventilation, ${ }^{28-30}$ and neonatal convulsions. ${ }^{27} 2831$ In a further study no consistency was found in factors predictive of cerebral palsy or developmental retardation between two adjacent hospitals. ${ }^{32}$ This lack of consistency is perhaps not surprising in view of current ideas that localised 
periventricular brain injury, rather than a specific series of clinical events, is important in the generation of later disabilities. None the less, these studies indicate some of the predisposing factors in the generation of such brain injury. The association of adverse clinical perinatal factors with later motor impairments in this study suggests that such impairments may indeed be acquired in the perinatal period, and that further studies are indicated.

It is of interest that the three clinical factors identified by this study are similar to the associates of periventricular leucomalacia found by Sinha et al. ${ }^{33}$ Cystic periventricular leucomalacia is clearly associated with later major impairments, and changes on cerebral ultrasound scanning correlate well with later cerebral palsy. ${ }^{6}$ Less severe ultrasound changes may be associated with lesser impairments, but the evidence presented in this study does not support this hypothesis. Ultrasound scans were, however, performed with the technology available in 1980-81. Higher frequency scan heads and better awareness of the natural history of minor ultrasound findings ${ }^{34}$ may reveal a more subtle association not identified by this study. It is, therefore, as yet not clear whether children with no cerebral palsy but poor motor skills have suffered similar but less severe brain injuries than those children with cerebral palsy.

Although considered to be performing satisfactorily in the infant school, this group of extremely low birthweight children have a wide range of minor abnormalities of motor, neurological, cognitive, and behavioural function. These problems are likely to become quantitatively more important when greater demands are made at junior school age and beyond. Children born before recent improvements in neonatal care have frequent educational problems. ${ }^{16} 172035$ Despite recent improvements in perinatal care it seems likely that such problems persist. Future research should be directed at defining the aetiology of such impairments and at their amelioration or prevention.

This project was supported by Mersey Regional Health Authority.

\section{References}

1 Marlow N, Chiswick ML. Neurodevelopmental outcome in extremely low birthweight survivors. In: Chiswick ML, ed. Recent advances in perinatal medicine. Vol. II. Edinburgh: Churchill Livingstone, 1985:181-205.

2 Lubchencho LO, Reed LH, Hix IE, et al. Sequelae of premature birth. Am J Dis Child 1963;106:111-5.

3 Drillien CM. The incidence of mental and physical handicaps at school age in children of very low birthweight. Pediatrics 1961;27:452-64.

+ Nickel RE, Bennett FC, Lamson FN. School performance of
}

children with birthweights of $1000 \mathrm{~g}$ or less. Am J Dis Child 1982;136:105-10.

5 Eilers BL, Desai NS, Wilson MA, Cunningham MD. Classroom performance and social factors of children with birthweights of $1250 \mathrm{~g}$ or less. Pediatrics 1986;77:203-8.

${ }^{6}$ Cooke RWI. Early and late cranial ultrasonographic appearances and outcome in very low birthweight infants. Arch Dis Child 1987;62:931-7.

7 Wechsler D. Manual for the Wechsler preschool and primary scales of intelligence. New York: Psychological Corporation, 1967.

${ }^{8}$ Stott DH, Moyes FA, Henderson SE. Test of motor impairment (Henderson revision). Guelph: Brook Educational, 1984.

9 Touwen BCL. Examination of the child with minor neurological dysfunction. Clinics in developmental medicine No 71. London: SIMP, 1979

10 Fog E, Fog M. Cerebral inhibition examined by associated movements. In: Bax M, MacKeith R, eds. Minimal cerebral dysfunction. Little Club Clinics in Developmental Medicine No. 10. London: National Spastics Society, 1963:52-7.

11 Hadders-Algra M, Touwen BCL, Olinga AA, Huisjes HJ. Minor neurological dysfunction and behavioural development: a report from the Groningen Perinatal Project. Early Hum Dev 1985;11:221-9.

12 Keen DV, Pearse RG. An analysis of body weight between 14 and 42 weeks gestation. Arch Dis Child 1985;60:440-6.

13 Drillien CM, Thomson AJM, Burgoyne K. Low birthweight children at early school age: a longitudinal study. Dev Med Child Neurol 1980;22:26-47.

14 Neligan GA, Kolvin I, Scott DMcL, Garside RF. Born too soon or born too small. Clinics in developmental medicine No 61 . London: SIMP, 1976:30-1.

15 MacKinlay I, England A, Nash S, et al. The predictive value of coordination testing. Neuropediatrics 1981;12(suppl):426.

16 Dunn HG, Ho HH, Schulzer M. Minimal brain dysfunctions. In: Dunn HG, ed. Sequelae of low birthweight: the Vancouver study. Oxford: MacKeith Press, 1986.

17 Illsley R, Mitchell RG, eds. Low birthweight: a medical, psychological and social study. Chichester: John Wiley, 1984.

18 Hunt JV, Tooley WH, Harvin D. Learning disabilities in children with birth weights $<1500$ grams. Semin Perinatol 1982;6:280-7.

19 Rutter M, Tizard J, Whitmore K. Education, health and behaviour. London: Longman, 1970.

${ }^{20}$ Michelsson $\mathbf{K}$, Noronen $\mathbf{M}$. Neurological, phychological and articulatory impairment in five-year-old children with a birthweight of $2000 \mathrm{~g}$ or less. Eur J Pediatr 1983;141:96-100.

${ }^{21}$ Brand C. Intelligence testing: bryter still and bryter? Nature 1987;328:110.

22 Astbury J, Orgill A, Bajuk B. Relationship between two year behaviour and neurodevelopmental outcome at five years of very low birthweight survivors. Dev Med Child Neurol 1987;29:370-9.

${ }^{23}$ Marlow N, D'Souza S, Chiswick ML. Neurodevelopmental outcome in babies weighing less than $2001 \mathrm{~g}$ at birth. $\mathrm{Br}$ Med J 1987;294:1582-6.

${ }^{24}$ Hertzig ME. Neurological 'soft' signs in low-birthweight children. Dev Med Child Neurol 1981;23:778-91.

${ }^{25}$ Shaffer D, Schonfeld I, O'Connor PA, et al. Neurological soft signs. Arch Gen Psychiatry 1985;42:342-51.

26 American Psychiatric Association. Diagnostic and statistical manual of mental disorders. 3rd ed. Washington: APA, 1980.

27 Bennett FC, Robinson NM, Sells CJ. Growth and development of infants weighing less than 800 grams at birth. Pediatrics 1983;71:319-323.

${ }^{28}$ Marlow N, Hunt LP, Chiswick ML. Clinical factors associated with adverse outcome for babies weighing $2000 \mathrm{~g}$ or less at birth. Arch Dis Child 1988;63:1131-6.

${ }^{29}$ Rothberg AD, Maisels MJ, Bagnato S, Murphy J, Gifford K, McKinley K. Infants weighing 1000 grams or less at birth: . 
developmental outcome for ventilated and non-ventilated infants. Pediatrics 1983;71:599-602.

30 Ruiz MPD, LeFever JA, Hakanson DO, Clark DA, Williams ML. Early development of infants of birthweight less than 1000 grams with reference to mechanical ventilation in the newborn period. Pediatrics 1981;68:330-5.

31 Yu VYH, Downe L, Astbury J, Bajuk B. Perinatal factors and adverse outcome in extremely low birthweight infants. Arch Dis Child 1986;61:554-8.

32 Kitchen WH, Yu VYH, Orgill AA, et al. Collaborative study of very low birthweight infants: correlation of handicap with risk factors. Am J Dis Child 1983;137:555-9.

${ }^{33}$ Sinha SK, Davies JM, Sims DG, Chiswick ML. Relation between periventricular haemorrhage and ischaemic brain lesions diagnosed by ultrasound in very pre-term infants. Lancet 1985;ii:1154-5.

34 Trounce JQ, Shaw DE, Levene MI, Rutter N. Clinical risk factors and periventricular leucomalacia. Arch Dis Child 1988;63:17-22.

${ }^{35}$ Francis-Williams J, Davis PA, Very low birthweight and later intelligence. Dev Med Child Neurol 1974;16:709-8.

Correspondence and request for reprints to $\mathrm{Dr} \mathrm{N}$ Marlow. Department of Child Health, Bristol Maternity Hospital, Southwell Street, Bristol BS2 8EG.

Accepted 9 January 1989 